\title{
Effect of a fever control protocol-based strategy on ventilator-associated pneumonia in severely brain-injured patients
}

Yoann Launey ${ }^{1,2,3^{*}}$, Nicolas Nesseler ${ }^{1,2,3}$, Audren Le Cousin $^{1,3}$, Fanny Feuillet ${ }^{4}$, Ronan Garlantezec ${ }^{5}$, Yannick Malldant ${ }^{1,2,3}$ and Philippe Seguin ${ }^{1,2,3}$

\begin{abstract}
Introduction: Fever is associated with a poor outcome in severely brain-injured patients, and its control is one of the therapies used in this condition. But, fever suppression may promote infection, and severely brain-injured patients are frequently exposed to infectious diseases, particularly ventilator-associated pneumonia (VAP). Therefore, we designed a study to explore the role of a fever control protocol in VAP development during neuro-intensive care.

Methods: An observational study was performed on severely brain-injured patients hospitalized in a university ICU. The primary goal was to assess whether fever control was a risk factor for VAP in a prospective cohort in which a fever control protocol was applied and in a historical control group. Moreover, the density of VAP incidence was compared between the two groups. The statistical analysis was based on a competing risk model multivariate analysis.

Results: The study included 189 brain-injured patients (intervention group, $n=98$, and historical control group, $n=91$ ). The use of a fever control protocol was an independent risk factor for VAP (hazard ratio 2.73, 95\% confidence interval $(1.38,5.38 ; P=0.005))$. There was a significant increase in the incidence of VAP in patients treated with a fever control protocol (26.1 versus 12.5 VAP cases per 1000 days of mechanical ventilation). In cases in which a fever control protocol was applied for $>3$ days, we observed a higher rate of VAP in comparison with the rate among patients treated for $\leq 3$ days.
\end{abstract}

Conclusions: Fever control in brain-injured patients was a major risk factor for VAP occurrence, particularly when applied for $>3$ days.

\section{Introduction}

In severely brain-injured patients, the incidence of fever in the first week of hospitalization approaches $87 \%$ [1]. Numerous studies have noted that fever in these patients is associated with a prolonged length of stay in the intensive care unit (ICU) and hospital, severe physical dependency, cognitive impairment and increased mortality $[2,3]$. Thus, fever control is a common therapy used to treat patients with severe brain injuries [4]. Nevertheless, specific guidelines concerning the optimal delay, length, means and target of temperature control are lacking $[4,5]$.

\footnotetext{
*Correspondence: yoann.launey@chu-rennes.fr

${ }^{1} \mathrm{CHU}$ de Rennes. Hpital Pontchaillou. Ple Anesthsie-SAMU-UrgencesRanimations. 2, rue Henri Le Guilloux, 35033 Rennes, Cedex, France ${ }^{2}$ Inserm UMR991, quipe 2: Stress, Defense and Regeneration . 2, rue Henri Le Guilloux, 35000 Rennes, France

Full list of author information is available at the end of the article
}

From another perspective, several experimental and clinical studies that have assessed fever control in other diseases have suggested that there are harmful effects associated with a fever control strategy [6-9]. These adverse effects of fever control, notably shivering, infectious diseases and/or hypotension, are negative factors affecting the prognoses of brain-injured patients $[10,11]$. In fact, fever, which is typically defined by an elevation of the core temperature above $38.2 \mathrm{C}[12,13]$, may be an adaptive response to injury when an infectious disease is ongoing [14]. Nosocomial infections, particularly ventilatorassociated pneumonia (VAP), are frequently observed in severely brain-injured patients, affecting from $8 \%$ to more than $70 \%$ of patients $[15,16]$. Therefore, we designed this study to define the role of a fever control protocol in VAP development during neuro-intensive care.

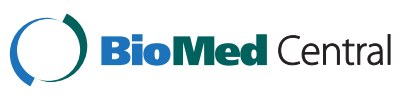

2014 Launey et al.; licensee BioMed Central. This is an Open Access article distributed under the terms of the Creative Commons Attribution License (http://creativecommons.org/licenses/by/4.0), which permits unrestricted use, distribution, and reproduction in any medium, provided the original work is properly credited. The Creative Commons Public Domain Dedication waiver (http://creativecommons.org/publicdomain/zero/1.0/) applies to the data made available in this article, unless otherwise stated. 


\section{Materials and methods}

This observational study was conducted between January 2008 and December 2009 in the surgical ICU of a university hospital, which received, among others, severely brain-injured patients. The criteria for selection included a severe brain injury (traumatic brain injury (TBI), subarachnoid hemorrhage (SAH), or intracranial hemorrhage), a Glasgow Coma Scale score $\leq 8$ and a need for mechanical ventilation (MV) for 48 hours or longer. Each selected patient underwent chart review. Patients who had aspiration pneumonia at admission or a brain computed tomography (CT) scan without any lesion or who received MV for less than 48 hours were excluded. This study was submitted to the local ethical committee of Rennes University Hospital (CHU Pontchaillou, Rennes, no. 14.45), which stated that no patient consent was needed.

In 2008, Greer et al. suggested that fever had a deleterious effect in brain-injured patients and that there was an evidence-based need to confirm the potential benefit of fever control in this population [2]. Consequently, from 1 January 2009 until 31 December 2009, a fever control protocol was applied in cases in which the core body temperature was $>38.2 \mathrm{C}$. Because the fever control protocol was the only therapeutic change, patients admitted from 1 January 2008 to 31 December 31 2008 served as historical controls. In the fever-control group, patients were prospectively and consecutively included, whereas in the historical control group, patients were identified and selected from the list of admissions to our ICU.

The primary endpoint was to assess whether fever control was a risk factor for VAP. The secondary endpoints were the density of incidence and the incidence of VAP, both nosocomial urinary tract infections (UTIs) and catheter-related bloodstream infections (CRBIs), the duration of MV, the length of stay in the ICU, and the mortality rate.

\section{Patient management}

During the two study periods, brain-injured patients were similarly managed according to identical local protocols based on international guidelines $[17,18]$. The two major objectives were as follows: 1 ) to infuse neurosedation combining midazolam and opioids; and 2) to maintain cerebral perfusion pressure $\geq 70 \mathrm{mmHg}$. All the patients were orotracheally intubated; VAP prevention measures included hand washing with alcohol based antiseptic, a 30 semi-recumbent patient position, MV with positive end-expiratory pressure $>5 \mathrm{mmHg}$, and oral care based on local application of povidone-iodine solution six times daily [15]. Selective digestive decontamination or subglottic drainage was not performed, and ulcer prophylaxis was not systematically administered. The core body temperature was continuously monitored with a rectal thermal probe (Mon-a-Therm , Covidien, Mansfield, MA, USA).

Fever control intervention was applied in cases in which the body core temperature was $>38.2 \mathrm{C}$ [12]. This protocol was established based on previously published studies $[4,19,20]$ and successively included the following: external cooling, an infusion of $500 \mathrm{~mL}$ of cooled (4C) saline serum and enteral administration of acetaminophen. A neuromuscular blocker (cisatracurium) was also used if shivering occurred. The objective was to reach a core body temperature of $36 \mathrm{C}$ to $38.2 \mathrm{C}$.

\section{Data collection and definitions}

Gender, age, body mass index, the reason for ICU admission, a history of smoking, a positive alcohol test at admission and CT scan-identified lung contusions involving more than one lobe were recorded for each patient at the time of admission to the ICU. The severity of the brain injury was assessed at admission using the Glasgow Coma Scale score and the Simplified Acute Physiological Score II (SAPS II) [21].

We collected the daily minimum (Tmin) and maximum (Tmax) body core temperature and calculated the mean daily temperature as $(\operatorname{Tmax}+\operatorname{Tmin}) / 2$ during the first eight days of ICU hospitalization. We reported the delay between ICU admission and the initiation of the fever control protocol, the length of application of the fever control protocol and mortality at ICU discharge. Antibiotic prophylaxis, neuromuscular blocker agents, mannitol and thiopental use was reported for all patients. Additionally, acute respiratory distress syndrome (ARDS), defined as previously [22], and microbiological findings for VAP were reported.

VAP was defined as new and persistent pulmonary infiltrates on a chest radiograph occurring after 48 hours of MV, combined with at least two of the following criteria: 1) purulent tracheal secretions and/or body core temperature $>38 \mathrm{C}$ and/or leukocytosis $>10,000 / \mathrm{mm}^{3}$ or leukopenia $<3,000 / \mathrm{mm}^{3}$; and 2) microbiological confirmation via an endotracheal aspirate quantitative culture growing $\geq 10^{6}$ colony forming units (cfu)/mL [23]. The occurrence of VAP was reported and expressed as the density of incidence, defined as the number of VAP cases per 1,000 ventilator-days. We also defined earlyonset VAP as VAP that occurred $\leq 5$ days after admission and late-onset VAP as VAP diagnosed $>5$ days, according the American Thoracic Society criteria [24].

UTIs and CRBIs were defined according to the CDC guidelines $[25,26]$.

\section{Statistical analysis}

The categorical parameters are expressed as number and frequency. The quantitative parameters are expressed as the mean (standard deviation) if there was a normal 
distribution or the median (interquartile range) otherwise. The categorical parameters were compared using the Chi-square test or, when necessary, Fisher's exact test. The quantitative parameters were compared using the two-tailed $t$-test (when normally distributed) or with the Mann Whitney $U$ test. The temperature value was recorded on the date of the VAP diagnosis. To determine risk factors for VAP occurrence, we used a competing risk model, as proposed by Fine and Gray [27]. VAP before the 28th day of hospitalization in the ICU was an event of interest but could be precluded by death before the 28th day of hospitalization. Patients were therefore observed from the day of hospitalization to the occurrence of VAP before the 28th day of hospitalization in the ICU, to death before the 28th day of hospitalization, or to censoring (hospital discharge while living, without VAP occurrence at day 28 or before). We first compared patient characteristics according to whether the fever control protocol was used to identify potential confounding factors existing before VAP occurrence. A univariate analysis was first performed. Variables with $P$-values $<0.20$ were then included in the multivariate competing risk model, and a backward selection was applied. The model was adjusted for the risk factors selected according to use of the fever control protocol. By stratifying the duration of fever control, we analyzed the effect of the duration of fever control on VAP occurrence. The adjusted hazard ratios (HRs) and their corresponding 95\% confidence intervals (CIs) were calculated, and the cumulative incidence curves for VAP were determined using the Nelson-Aalen non-parametric estimator. By stratifying the fever control duration, we could also describe the impact of the fever control duration on VAP based on the cumulative incidence curve with the Nelson-Aalen non-parametric estimator. A two-sided $P$-value $<0.05$ was considered statistically significant. The statistical models were built using SAS 9.3 (SAS Institute, Inc., Cary, NC, USA) and $\mathrm{R}$ Core Team (2012) software (R: A language and environment for statistical computing. R Foundation for Statistical Computing, Vienna, Austria).

\section{Results}

During the study period, 331 brain-injured patients were screened, and 189 were included (intervention group, $\mathrm{n}=98$; historical control group, $\mathrm{n}=91$ ) (Figure 1). The primary characteristics of the patients are presented in Table 1. The proportion of subarachnoid hemorrhaging was significantly higher in the intervention group than in the historical control group (28\% versus $14 \%$, respectively; $P=$ 0.006). The clinical characteristics are reported in Table 2.

\section{Management of the fever control protocol}

All patients in the intervention group were treated with the fever control protocol when their fever was $>38.2 \mathrm{C}$.
The delay before its effective application was less than 24 hours, and its median duration was four days (range, two to six days). The daily mean temperature curves for each group are displayed in Figure 2.

The density of the incidence of VAP was significantly increased in the intervention group beginning on ICU day 5 (26.1 versus 12.5 VAP cases per 1,000 days of ventilation; $P<0.001)$. The incidence of VAP was $38 \%(\mathrm{n}=37)$ versus $12 \%(\mathrm{n}=11)$ for the intervention group and historical control group, respectively. The mean delay for VAP occurrence was similar in the two groups ( 84 days). The mean length of $\mathrm{MV}$ was significantly increased in the intervention group (15 11 versus 107 days, $\quad P<0.001$ ). Methicillin-sensitive Staphylococcus aureus (MSSA), Streptococcus pneumoniae and Haemophilus influenzae comprised $80 \%$ of the microbiological findings. The microbiological findings are detailed in Table 3. Considering the VAP-onset delay, we reported 10 early-onset VAP cases in the intervention group compared with 5 in the historical control group and 27 late-onset VAP cases in the intervention group compared with 6 in the historical control group.

The densities of incidence of UTIs and CRBIs were not significantly different between the intervention and the historical control groups (9.7 versus 14.7 UTIs per 1,000 urinary catheter-days, respectively; $P=0.9 ; 3.9$ versus 1.6 CRBIs per 1,000 catheter-days, respectively; $P=0.19$ ). The mortality rate also did not differ between the two groups (34\% in the intervention group versus $23 \%$ in the historical control group; $P=0.107$ ).

In the univariate analysis (Table 4), the patients who developed VAP were significantly younger, used tobacco more frequently and had more extensive lung injury at admission to the ICU. Application of the fever control protocol was a major risk factor for developing VAP (HR 3.06; 95\% CI $(1.58,5.94))$. In the multivariate analysis, the competing risk model was built after adjustment of the HR for a history of smoking, age, the SAPS II score, pentothal use and the use of neuromuscular blocker agents. The use of the fever control protocol was the only significant independent risk factor for VAP occurrence (HR 2.73, 95\% CI $(1.38,5.38)$ ) (Table 4). The cumulative incidence function curves for VAP are displayed in Figure 3. The risk of VAP appeared to be higher when the duration of the fever control protocol was $>3$ days (Figure 4).

\section{Discussion}

In this study, we found that the use of a fever control protocol during the early management of critically braininjured patients was associated with an increased risk of VAP. During ICU hospitalization of brain-injured patients, sepsis and VAP are major causes of death [23]. In particular, VAP is estimated to occur in $25 \%$ to $70 \%$ of critically ill 


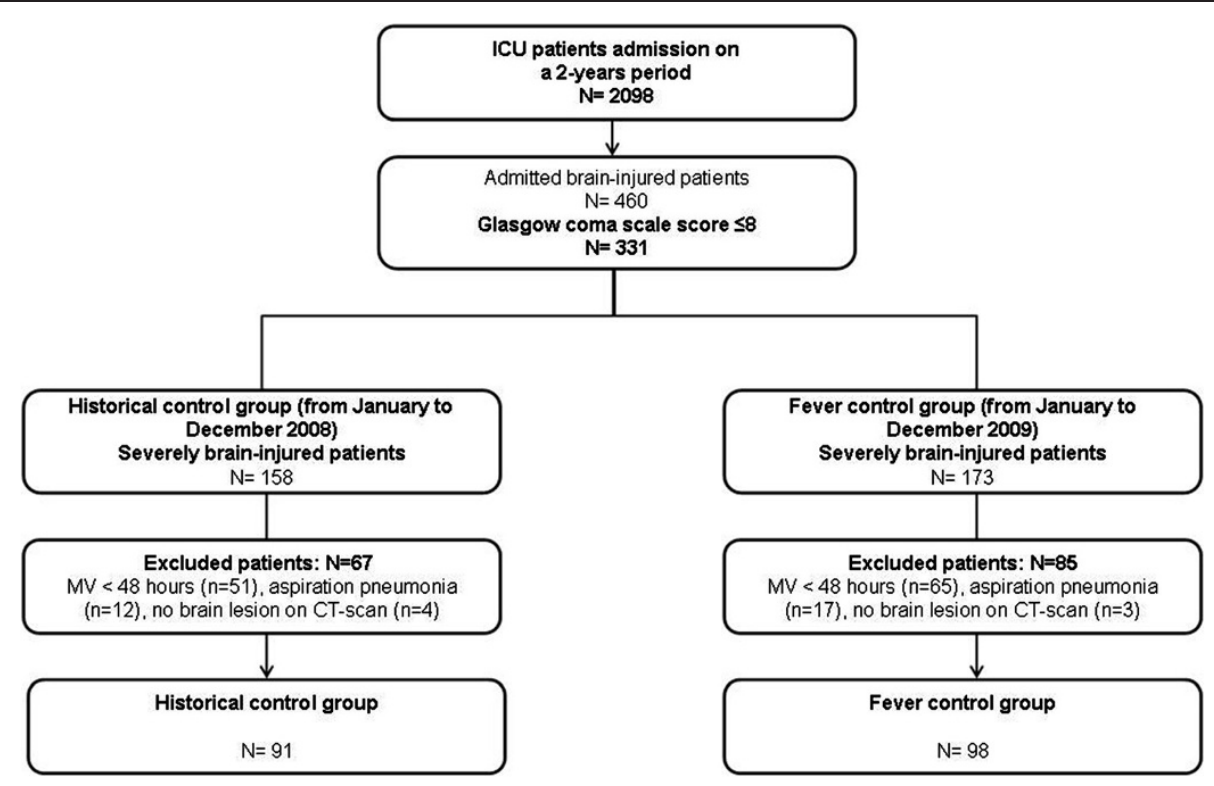

Figure 1 Flowchart of the study inclusion scheme. MV: mechanical ventilation.

patients $[23,28,29]$. The incidence of VAP in our severely brain-injured patients was $26 \%$, and the microbiological results were relatively similar to those of previous studies $[15,30,31]$, which predominantly found the following microorganisms: MSSA, Haemophilus influenzae and Streptococcus pneumoniae. It is noteworthy that VAP incidence could be underestimated in the intervention group because fever is a clinical sign of VAP; consequently, the difference in VAP occurrence between the two groups could be minimized. The deleterious effect of such infections has recently been reported in two meta-

Table 1 Baseline characteristics

\begin{tabular}{lllc}
\hline Baseline characteristics & $\begin{array}{l}\text { Intervention group } \\
\text { Number = 98 }\end{array}$ & $\begin{array}{l}\text { Control group } \\
\text { Number = 91 }\end{array}$ & $\begin{array}{l}\text { P-value } \\
\text { Age }\end{array}$ \\
Gender (male) & $72(73 \%$ to 57$)$ & $53(27$ to 66$)$ & 0.022 \\
BMI & 254 & $64(70 \%)$ & 0.631 \\
Reason for admission & & 245 & 0.123 \\
$\quad$ TBI & $64(65 \%)$ & $61(67 \%)$ & 0.012 \\
$\quad$ SAH & $27(28 \%)$ & $13(14 \%)$ & \\
$\quad$ ICH & $7(7 \%)$ & $17(19 \%)$ & \\
Smoking & $38(39 \%)$ & $23(25 \%)$ & 0.048 \\
Positive alcohol test & $11(11 \%)$ & $14(15 \%)$ & 0.399 \\
Lung contusion & $28(29 \%)$ & $17(19 \%)$ & 0.111 \\
GCS & $6(3$ to 8$)$ & $6(3$ to 7$)$ & 0.338 \\
SAPS II & 4911 & 5314 & 0.013 \\
\hline
\end{tabular}

BMI: body mass index; GCS: Glasgow Coma Scale; ICH: intracranial hemorrhage; SAH: subarachnoid hemorrhage; SAPS II: Simplified Acute Physiology Score II; TBI: traumatic brain injury. analyses, which showed that VAP was associated with increased mortality [32,33]. However, in a subgroup of trauma patients, no significant increase in mortality was observed [33].

VAP in severely brain-injured patients has a different pattern than in other critically ill patients. Several factors favor the development of VAP. In brain-injured patients, VAP typically occurs early in the ICU stay, between day 5 and day 11 after hospitalization. The presence of abnormal protection of the glottal area and consecutive early micro-inhalation is typically suggested to explain the occurrence of VAP. These aspirations predominantly contain oropharyngeal bacteria from the commensal flora of the patient, as shown by Ewig et al. [34]. In this context, pneumonia results from extensive tracheal and bronchial inocula in patients with altered immune responses and ventilation-related impairment (including due to an endotracheal tube, sedation, or neuromuscular blockers) [35,36].

Fever may be an adaptive response to injury, particularly in cases of ongoing infectious disease. When this response is suppressed, several studies have indicated an increased risk of infectious disease and, especially, VAP. In particular, randomized studies have shown an increased rate of VAP in groups treated with therapeutic hypothermia $[37,38]$. For instance, although the methodology is debatable, a meta-analysis including eight studies of patients with TBIs reported an increased rate of VAP in the group receiving therapeutic hypothermia (OR 2.37, 95\% CI (1.37, 4.10)) [37]. Similarly, Geurts et al. found an increased risk of VAP (risk ratio 1.44, $95 \%$ CI $(1.10,1.90)$ ) and sepsis (risk ratio $1.80,95 \%$ CI 
Table 2 Clinical characteristics during ICU management

\begin{tabular}{|c|c|c|c|}
\hline \multirow[t]{2}{*}{ Clinical characteristics } & \multirow{2}{*}{$\begin{array}{l}\text { Intervention } \\
\text { group } \\
\text { Number }=98\end{array}$} & $\begin{array}{l}\text { Control } \\
\text { group }\end{array}$ & \multirow[t]{2}{*}{$P$-value } \\
\hline & & Number $=91$ & \\
\hline ARDS, yes & $4(4 \%)$ & $2(2 \%)$ & 0.684 \\
\hline Antibiotic prophylaxis & $43(44 \%)$ & $43(47 \%)$ & 0.645 \\
\hline NMB agents & $13(13 \%)$ & $5(5 \%)$ & 0.116 \\
\hline Pentothal use, yes & $39(40 \%)$ & $19(21 \%)$ & 0.005 \\
\hline Mannitol use, yes & 49 (50\%) & $21(23 \%)$ & $<0.001$ \\
\hline ICU length of stay, days & 1713 & 118 & $<0.001$ \\
\hline Mortality, number (\%) & $23(23 \%)$ & $31(34 \%)$ & 0.107 \\
\hline
\end{tabular}

ARDS: acute respiratory distress syndrome; ICU: intensive care unit; NMB: neuromuscular blocker.

$(1.04,3.10))$ in patients treated with therapeutic hypothermia, regardless of what surface or endovascular cooling devices were used [38].

To overcome this adverse effect, normothermia-targeted temperature management has been suggested. However, data on the effects of normothermia in neurologically injured patients are limited. Several studies have investigated and compared the efficacy of different devices in maintaining normothermia but, despite their conclusions, have reported no difference in adverse effects. These studies were not designed to evaluate the rate of infection [39-41]. Additionally, Puccio et al. retrospectively compared the effects of a normothermia protocol on TBI management
[42]. They found a beneficial effect on intracranial pressure and on the duration of intracranial hypertension episodes in the normothermia group. The systematic initiation of a normothermia protocol, even prophylactically, allowed fever control and possibly attenuation of secondary brain injuries. Similarly, Badjatia et al. assessed the effect of normothermia in $\mathrm{SAH}$ in a case control study [11]. They found better fever control, without a significant increase in the rate of VAP (a 58\% rate of VAP in the therapeutic normothermia group versus $51 \%$ in the historical control group; $P=0.08$ ).

In our study, we observed that a sustained intervention for $>3$ days was more likely to aggravate the incidence of VAP compared with an intervention with a duration of $\leq 3$ days. To the best of our knowledge, no previous study has investigated the effect of the duration of normothermia. It appears that the targeted body temperature does not affect VAP occurrence; however, counteracting the physiological fever response to stress and its duration may be a key factor in the increased occurrence of VAP. More specifically, although fever is deleterious in the short and medium term in braininjured patients, fever control, whether by hypo- or normothermia, allows reduction of the intracranial pressure at the expense of increased susceptibility to infections. Moreover, in therapeutic hypothermia, the hypothesized anti-inflammatory effect has been associated with impaired cellular and humoral immunity [43]. Unfortunately,

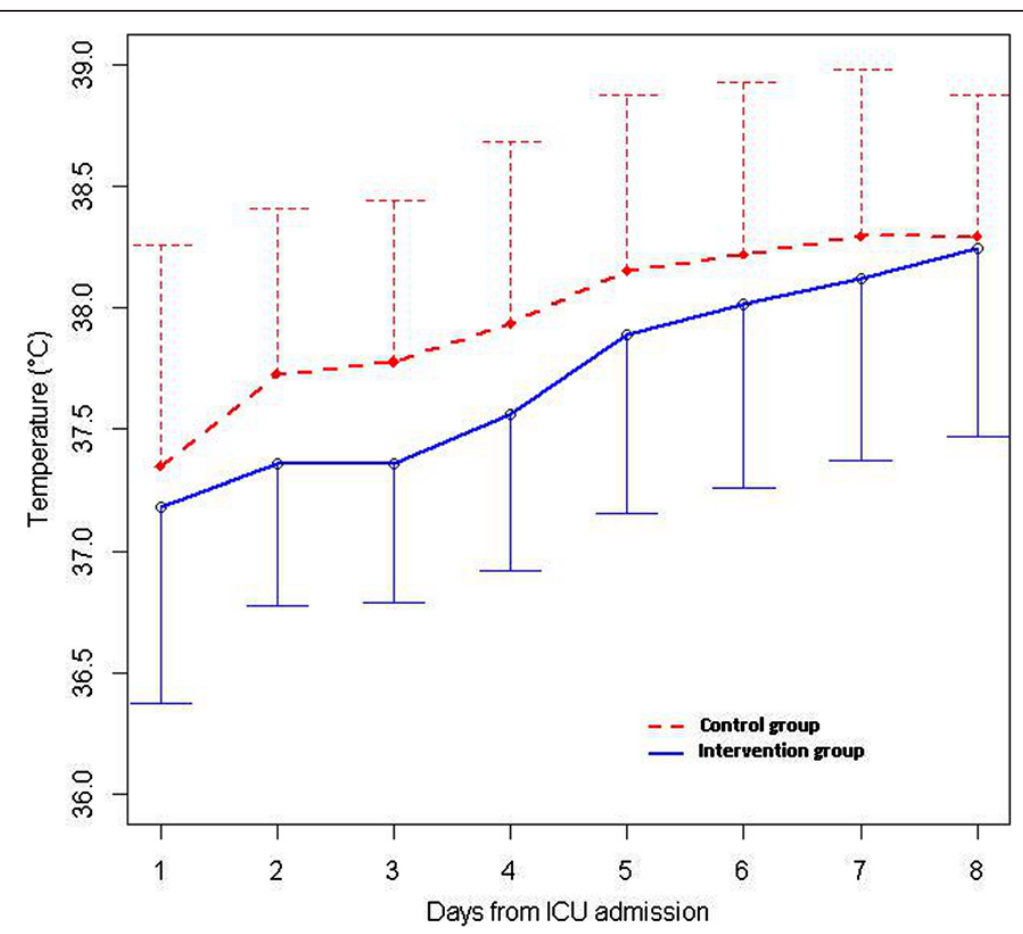

Figure 2 Mean daily body core temperature curves for the first eight days of ICU stay. Upper (dashed line) and lower (dark line) limits of standard deviation are displayed for the control group and the intervention group, respectively. 
Table 3 Microbiological findings for VAP

\begin{tabular}{lccc}
\hline Bacterium & Total & $\begin{array}{l}\text { Intervention } \\
\text { group }\end{array}$ & $\begin{array}{l}\text { Control } \\
\text { group }\end{array}$ \\
& Number $=\mathbf{6 2}$ & Number = 48 & Number $=\mathbf{1 4}$ \\
\hline Gram-positive cocci & 22 & 17 & 5 \\
MSSA & 1 & 0 & 1 \\
MRSA & 11 & 8 & 3 \\
Streptococcus pneumoniae & 1 & 0 & 1 \\
Streptococcus anginosus & 17 & 14 & \\
Gram-negative bacilli & 3 & 3 & 0 \\
Haemophilus influenzae & 1 & 0 & 1 \\
Escherichia coli & 1 & 1 & 0 \\
Moraxella catarrhalis & 1 & 1 & 0 \\
Klebsiella oxytoca & 1 & 1 & 0 \\
Proteus mirabilis & 1 & 1 & 0 \\
Citrobacter freundii & 1 & 1 & 0 \\
Enterobacter cloacae & Acinetobacter baumannii & 17 & \\
\hline
\end{tabular}

MSSA: methicillin-sensitive Staphylococcus aureus; MRSA: methicillin-resistant Staphylococcus aureus; VAP: ventilator-associated pneumonia.

to our knowledge, no study has assessed the underlying brain physiology in fever control targeting normothermia.

Concerning the strengths and limitations of our study, the survey of major nosocomial infections in our ICU was prospective starting in 2002, and the diagnostic criteria did not change between the two study periods. Although the use of competing risk models in the multivariate analysis ensured the strength of our study, the major limitation is the design of the study, which used a historical control group, consequently implying limited matching between the two study groups. The interpretation of the results should consider the difference in the mean age and the reason for admission between each group, particularly the higher number of SAH in the control group. Additionally, we have accounted for the confounding factors that may impact the occurrence of VAP, but red blood cell transfusion, level of sedation and antibiotic use during ICU stay were not reported. Head of bed elevation was not reported but standard care in our ICU uses a 30 semirecumbent patient position. Finally, the fever threshold chosen to start the fever control protocol should be discussed; certain studies have used a temperature threshold of 38C to start fever control interventions, but solid evidence to clearly support this threshold is lacking.

\section{Conclusions}

Protocol-based control of fever in patients with severe head injuries is associated with an increased risk of VAP during the patients ICU stay. Our results suggest that when targeted normothermia is used, the probability of developing an infectious fever within 72 hours is low. However, if fever occurs later, the probability of an infectious fever is higher and should alert intensivists to an ongoing infection. Because data on the impact of fever control and its side effects on the outcome of braininjured patients are scarce, a large randomized study is required.

\section{Key messages}

The fever control in severely brain-injured patients is a major risk factor for VAP. Moreover, the VAP rate appears to be higher if fever control lasts longer than 3 days.

Table 4 Risk factors for VAP occurrence before day 28 (univariate and multivariate analyses)

\begin{tabular}{|c|c|c|c|c|c|c|}
\hline \multirow[t]{2}{*}{ Parameters } & \multicolumn{3}{|c|}{ Univariate analysis } & \multicolumn{3}{|c|}{ Multivariate analysis } \\
\hline & HR & $95 \% \mathrm{Cl}(\mathrm{HR})$ & $P$-value & HR & $95 \% \mathrm{Cl}(\mathrm{HR})$ & $P$-value \\
\hline Age & 0.97 & $(0.95,0.98)$ & $<0.001$ & 0.97 & $(0.95,0.98)$ & $<0.001$ \\
\hline Gender (male) & 1.82 & $(0.88,3.78)$ & 0.110 & & & \\
\hline BMI & 0.99 & $(0.93,1.05)$ & 0.730 & & & \\
\hline Smoking & 1.89 & $(1.09,3.30)$ & 0.024 & 1.67 & $(0.95,2.93)$ & 0.078 \\
\hline Alcohol intake & 0.85 & $(0.35,2.09)$ & 0.730 & & & \\
\hline Lung contusion & 2.41 & $(1.37,4.24)$ & 0.002 & & & \\
\hline GCS & 0.97 & $(0.85,1.12)$ & 0.710 & & & \\
\hline SAPS $\|$ & 0.98 & $(0.95,1.00)$ & 0.068 & 1.01 & $(0.98,1.04)$ & 0.590 \\
\hline NMB agents & 2.11 & $(0.97,4.61)$ & 0.061 & & & \\
\hline Mannitol & 1.25 & $(0.72,2.17)$ & 0.430 & & & \\
\hline Thiopental & 1.36 & $(0.78,2.38)$ & 0.270 & 0.95 & $(0.53,1.69)$ & 0.950 \\
\hline Fever control & 3.06 & $(1.58,5.94)$ & $<0.001$ & 2.73 & $(1.38,5.38)$ & 0.005 \\
\hline
\end{tabular}

BMI: body mass index; GCS: Glasgow Coma Scale; NMB: neuromuscular blocker; SAPS II: Simplified Acute Physiology Score II; VAP: ventilator-associated pneumonia. 


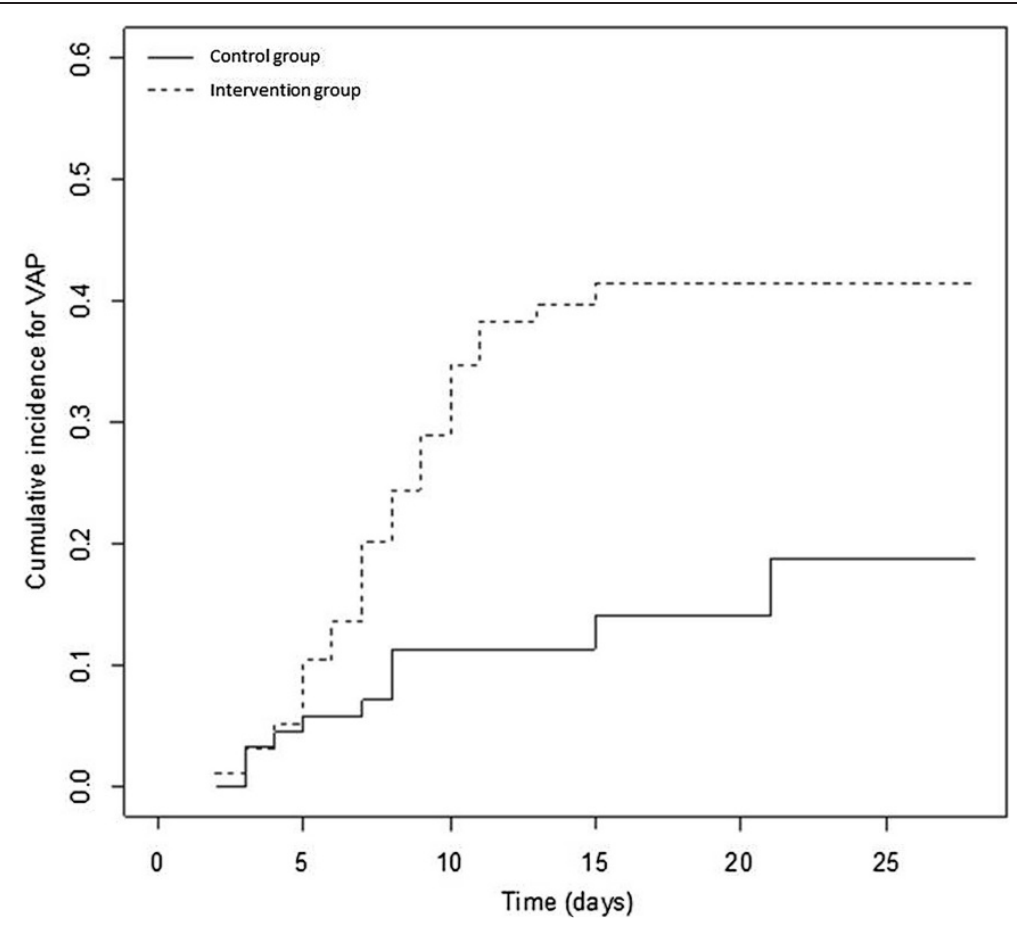

Figure 3 Cumulative incidence function curve for VAP occurrence according to fever control protocol management. The non-parametric estimator according to Nelson-Aalen. VAP: ventilator-associated pneumonia.

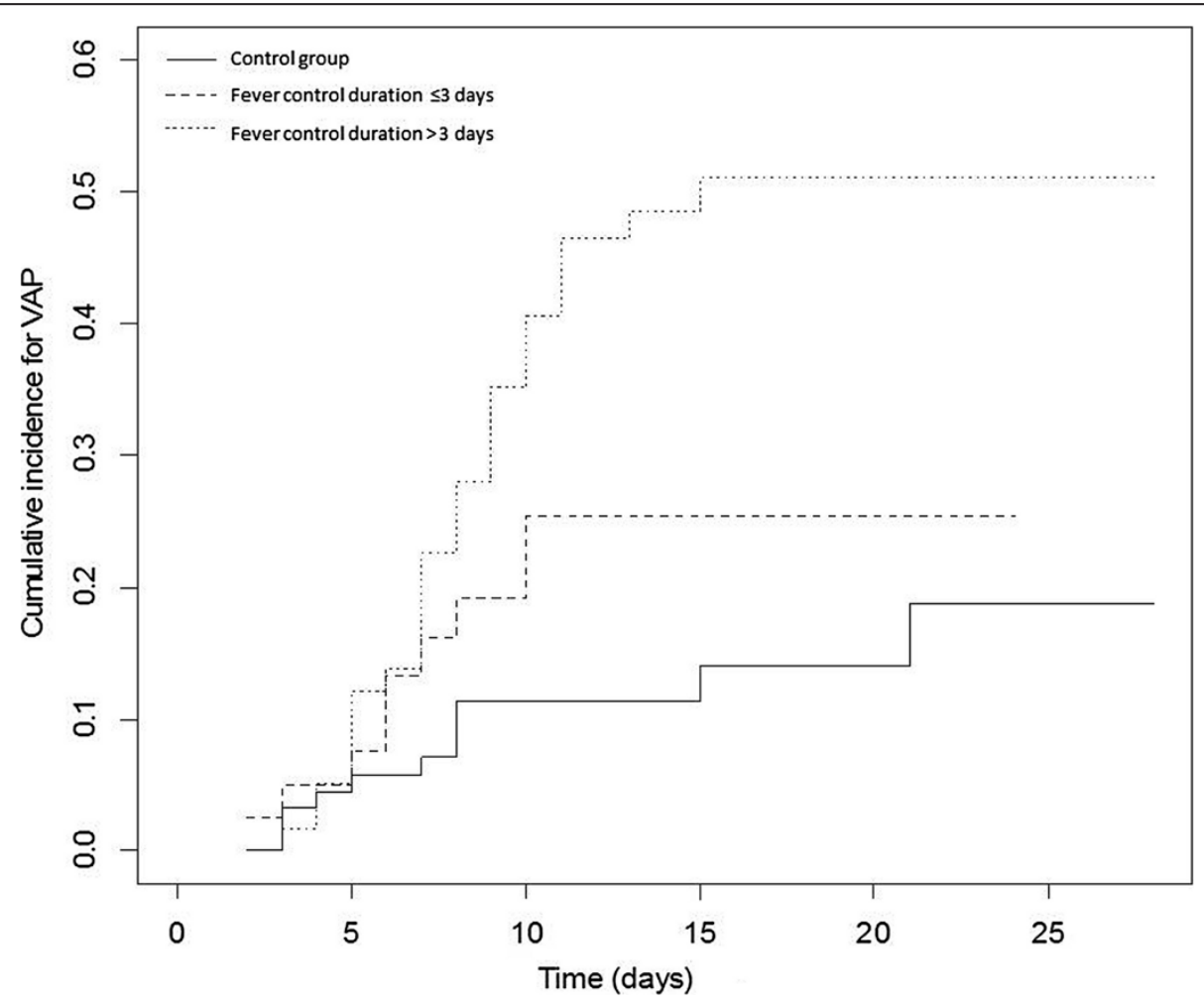

Figure 4 Cumulative incidence function curve for VAP occurrence according to the duration of the fever control protocol when applied. VAP: ventilator-associated pneumonia. 


\section{Abbreviations}

ARDS: acute respiratory distress syndrome; $\mathrm{Cl}$ : confidence interval; CRBI: catheter-related bloodstream infection; $C T$ : computed tomography; HR: hazard ratio; ICU: intensive care unit; MSSA: methicillin-sensitive Staphylococcus aureus; MV: mechanical ventilation; SAH: subarachnoid hemorrhage; SAPS II: Simplified Acute Physiological Acore II; TBI: traumatic brain injury; UTI: urinary tract infection; VAP: ventilator-associated pneumonia.

\section{Competing interests}

The authors declare that they have no competing interests.

\section{Authors contributions}

$\mathrm{YL}, \mathrm{AL}$ and PS designed and initiated the study. AL collected data and created the database of brain-injured patients. RG and FF participated in the statistical analysis of the data. YL, AL, PS and FF created the tables and figures. $Y L, A L, N N, P S$ and $Y M$ interpreted the data. $Y L, N N, P S$ and $Y M$ contributed in the writing of the manuscript. All authors read and approved the manuscript.

\section{Author details}

${ }^{1} \mathrm{CHU}$ de Rennes. Hpital Pontchaillou. Ple Anesthsie-SAMU-UrgencesRanimations. 2, rue Henri Le Guilloux, 35033 Rennes, Cedex, France. ${ }^{2}$ Inserm UMR991, quipe 2: Stress, Defense and Regeneration . 2, rue Henri Le Guilloux, 35000 Rennes, France. ' Universit Rennes 1, 35033 Rennes, Cedex, France. ${ }^{4}$ Plateforme de Biomtrie Cellule de promotion la recherche clinique, CHU Nantes, EA 4275 SPHERE Biostatistics, Pharmacoepidemiology \& Human Sciences Research, UFR de Pharmacie, Universit de Nantes. 1, rue Gaston Veil, 44000 Nantes, France. ${ }^{5}$ Ecole Nationale Hautes Etudes de Sant Publique. 2, Avenue du Professeur Lon Bernard, 35033 Rennes, Cedex, France.

Received: 18 July 2014 Accepted: 25 November 2014

Published online: 15 December 2014

\section{References}

1. Stocchetti N, Rossi S, Zanier ER, Colombo A, Beretta L, Citerio G: Pyrexia in head-injured patients admitted to intensive care. Intensive Care Med 2002, 28:1555 1562

2. Greer DM, Funk SE, Reaven NL, Ouzounelli M, Uman GC: Impact of fever on outcome in patients with stroke and neurologic injury: a comprehensive meta-analysis. Stroke 2008, 39:3029 3035.

3. Diringer MN, Reaven NL, Funk SE, Uman GC: Elevated body temperature independently contributes to increased length of stay in neurologic intensive care unit patients. Crit Care Med 2004, 32:1489 1495.

4. Badjatia N: Hyperthermia and fever control in brain injury. Crit Care Med 2009, 37:S250 \$257.

5. Mcllvoy L: Fever management in patients with brain injury. AACN Adv Crit Care 2012, 23:204 211.

6. Jiang Q, Cross AS, Singh IS, Chen TT, Viscardi RM, Hasday JD: Febrile core temperature is essential for optimal host defense in bacterial peritonitis. Infect Immun 2000, 68:1265 1270.

7. Su F, Nguyen ND, Wang Z, Cai $Y$, Rogiers $P$, Vincent JL: Fever control in septic shock: beneficial or harmful? Shock 2005, 23:516 520

8. Hersch M, Raveh D, lzbicki G: Effect of intravenous propacetamol on blood pressure in febrile critically ill patients. Pharmacotherapy 2008 28:1205 1210 .

9. Schulman Cl, Namias N, Doherty J, Manning RJ, Li P, Alhaddad A, Lasko D, Amortegui J, Dy CJ, Dlugasch L, Baracco G, Cohn SM: The effect of antipyretic therapy upon outcomes in critically ill patients: a randomized, prospective study. Surg Infect 2005, 6:369 375.

10. Oddo M, Frangos S, Maloney-Wilensky E, Andrew Kofke W, Le Roux PD, Levine JM: Effect of shivering on brain tissue oxygenation during induced normothermia in patients with severe brain injury. Neurocrit Care 2010, 12:10 16

11. Badjatia N, Fernandez L, Schmidt JM, Lee K, Claassen J, Connolly ES, Mayer SA: Impact of induced normothermia on outcome after subarachnoid hemorrhage: a case control study. Neurosurgery 2010, 66:696 700. discussion 700701

12. O Grady NP, Barie PS, Bartlett JG, Bleck T, Carroll K, Kalil AC, Linden P, Maki DG, Nierman D, Pasculle W, Masur $\mathrm{H}$ : Guidelines for evaluation of new fever in critically ill adult patients: 2008 update from the American
College of Critical Care Medicine and the Infectious Diseases Society of America. Crit Care Med 2008, 36:1330 1349.

13. Dellinger RP, Levy MM, Carlet JM, Bion J, Parker MM, Jaeschke R, Reinhart $K$, Angus DC, Brun-Buisson C, Beale R, Calandra T, Dhainaut JF, Gerlach H, Harvey M, Marini JJ, Marshall J, Ranieri M, Ramsay G, Sevransky J, Thompson BT, Townsend S, Vender JS, Zimmerman JL, Vincent JL: Surviving Sepsis Campaign: international guidelines for management of severe sepsis and septic shock: 2008. Crit Care Med 2008, 36:296 327.

14. Launey $Y$, Nesseler N, Malldant $Y$, Seguin P: Clinical review: fever in septic ICU patients friend or foe? Crit Care 2011, 15:222.

15. Seguin P, Tanguy M, Laviolle B, Tirel O, Malldant Y: Effect of oropharyngeal decontamination by povidone-iodine on ventilatorassociated pneumonia in patients with head trauma. Crit Care Med 2006, 34:1514 1519.

16. Roquilly A, Mahe PJ, Seguin P, Guitton C, Floch H, Tellier AC, Merson L, Renard B, Malledant Y, Flet L, Sebille V, Volteau C, Masson D, Nguyen JM, Lejus $C$, Asehnoune K: Hydrocortisone therapy for patients with multiple trauma: the randomized controlled HYPOLYTE study. JAMA 2011, 305:1201 1209.

17. Bratton SL, Chestnut RM, Ghajar J, McConnell Hammond FF, Harris OA, Hartl R, Manley GT, Nemecek A, Newell DW, Rosenthal G, Schouten J, Shutter L, Timmons SD, Ullman JS, Videtta W, Wilberger JE, Wright DW: Guidelines for the management of severe traumatic brain injury. I. Blood pressure and oxygenation. J Neurotrauma 2007, 24 Suppl 1:S7 S13.

18. Connolly ES, Rabinstein AA, Carhuapoma JR, Derdeyn CP, Dion J, Higashida RT, Hoh BL, Kirkness CJ, Naidech AM, Ogilvy CS, Patel AB, Thompson BG, Vespa P: Guidelines for the management of aneurysmal subarachnoid hemorrhage: a guideline for healthcare professionals from the American Heart Association/American Stroke Association. Stroke 2012, 43:1711 1737

19. Badjatia N, Bodock M, Guanci M, Rordorf GA: Rapid infusion of cold saline (4 degrees $\mathrm{C}$ ) as adjunctive treatment of fever in patients with brain injury. Neurology 2006, 66:1739 1741

20. Aiyagari $\mathrm{V}$, Diringer $\mathrm{MN}$ : Fever control and its impact on outcomes: what is the evidence? J Neurol Sci 2007, 261:39 46.

21. Le Gall JR, Lemeshow S, Saulnier F: A new Simplified Acute Physiology Score (SAPS II) based on a European/North American multicenter study. JAMA 1993, 270:2957 2963.

22. Bernard GR, Artigas A, Brigham KL, Carlet J, Falke K, Hudson L, Lamy M, Legall JR, Morris A, Spragg R: The American-European Consensus Conference on ARDS. Definitions, mechanisms, relevant outcomes, and clinical trial coordination. Am J Respir Crit Care Med 1994, 149:818 824.

23. Chastre J, Fagon JY: Ventilator-associated pneumonia. Am J Respir Crit Care Med 2002, 165:867 903.

24. American Thoracic Society, Infectious Diseases Society of America: Guidelines for the management of adults with hospital-acquired, ventilator-associated, and healthcare-associated pneumonia. Am J Respir Crit Care Med 2005, 171:388 416.

25. Centers for Disease Control and Prevention: Catheter-associated urinary tract infection (CAUTI) event. In CDC/NHSN Surveill Defin Specif Types Infect, Volume 7. 2014:1 15

26. Centers for Diseases Control and Prevention: Central line-associated bloodstream infection (CLABSI) event. In CDC/NHSN Surveill Defin Specif Types Infect, Volume 7. 2014. 4:1 19.

27. Fine J, Gray R: A Proportional hazards model for the subdistribution of a competing risk. J Am Stat Assoc 1999, 94:496 509.

28. Royon V, Guitard PG, Abriou C, Frebourg N, Menard JF, Clavier T, Dureuil B, Veber B: Hypothermia at admission increases the risk of pulmonary contusion s infection in intubated trauma patients. Ann Fr Anesthsie Ranimation 2012, 31:870 875.

29. Tejada Artigas A, Bello Dronda S, Chacn Valls E, Muoz Marco J, Villuendas Usn MC, Figueras P, Suarez FJ, Hernndez A: Risk factors for nosocomial pneumonia in critically ill trauma patients. Crit Care Med 2001, 29:304 309.

30. Bronchard R, Albaladejo P, Brezac G, Geffroy A, Seince PF, Morris W, Branger C, Marty J: Early onset pneumonia: risk factors and consequences in head trauma patients. Anesthesiology 2004, 100:234 239.

31. Sirvent JM, Torres A, Vidaur L, Armengol J, de Batlle J, Bonet A: Tracheal colonisation within $24 \mathrm{~h}$ of intubation in patients with head trauma: risk factor for developing early-onset ventilator-associated pneumonia. Intensive Care Med 2000, 26:1369 1372. 
32. Melsen WG, Rovers MM, Koeman M, Bonten MJM: Estimating the attributable mortality of ventilator-associated pneumonia from randomized prevention studies. Crit Care Med 2011, 39:2736 2742.

33. Melsen WG, Rovers MM, Groenwold RH, Bergmans DC, Camus C, Bauer TT, Hanisch EW, Klarin B, Koeman M, Krueger WA, Lacherade JC, Lorente L, Memish ZA, Morrow LE, Nardi G, van Nieuwenhoven CA, O Keefe GE, Nakos G, Scannapieco FA, Seguin P, Staudinger T, Topeli A, Ferrer M, Bonten MJ: Attributable mortality of ventilator-associated pneumonia: a metaanalysis of individual patient data from randomised prevention studies. Lancet Infect Dis 2013, 13:665 671.

34. Ewig S, Torres A, El-Ebiary M, Fbregas N, Hernndez C, Gonzlez J, Nicols $J M$, Soto L: Bacterial colonization patterns in mechanically ventilated patients with traumatic and medical head injury. Incidence, risk factors, and association with ventilator-associated pneumonia. Am J Respir Crit Care Med 1999, 159:188 198.

35. George DL, Falk PS, Wunderink RG, Leeper KV Jr, Meduri GU, Steere EL, Corbett CE, Mayhall CG: Epidemiology of ventilator-acquired pneumonia based on protected bronchoscopic sampling. Am J Respir Crit Care Med 1998, 158:1839 1847.

36. Hubmayr RD, Burchardi $H$, Elliot M, Fessler $H$, Georgopoulos D, Jubran A, Limper A, Pesenti A, Rubenfeld G, Stewart T, Villar J, American Thoracic Society Assembly on Critical Care, European Respiratory Society, European Society of Intensive Care Medicine, Socit de Ranimation de Langue Franaise: Statement of the 4th International Consensus Conference in Critical Care on ICU-Acquired Pneumonia Chicago, Illinois, May 20. Intensive Care Med 2002, 28:1521 1536.

37. Peterson K, Carson S, Carney N: Hypothermia treatment for traumatic brain injury: a systematic review and meta-analysis. J Neurotrauma 2008, 25:62 71.

38. Geurts M, Macleod MR, Kollmar R, Kremer PHC, van der Worp HB: Therapeutic hypothermia and the risk of infection: a systematic review and meta-analysis. Crit Care Med 2014, 42:231 242.

39. Badjatia N, O Donnell J, Baker JR, Huang D, Ayata C, Greer DM, Carter BS, Ogilvy CS, McDonald CT: Achieving normothermia in patients with febrile subarachnoid hemorrhage: feasibility and safety of a novel intravascular cooling catheter. Neurocrit Care 2004, 1:145 156.

40. Diringer MN, Neurocritical Care Fever Reduction Trial Group: Treatment of fever in the neurologic intensive care unit with a catheter-based heat exchange system. Crit Care Med 2004, 32:559 564

41. Broessner G, Beer R, Lackner P, Helbok R, Fischer M, Pfausler B, Rhorer J, Kppers-Tiedt L, Schneider D, Schmutzhard E: Prophylactic, endovascularly based, long-term normothermia in ICU patients with severe cerebrovascular disease: bicenter prospective, randomized trial. Stroke J Cereb Circ 2009, 40:e657 e665.

42. Puccio AM, Fischer MR, Jankowitz BT, Yonas H, Darby JM, Okonkwo DO: Induced normothermia attenuates intracranial hypertension and reduces fever burden after severe traumatic brain injury. Neurocrit Care 2009, 11:82 87.

43. Sahuquillo J, Vilalta A: Cooling the injured brain: how does moderate hypothermia influence the pathophysiology of traumatic brain injury. Curr Pharm Des 2007, 13:2310 2322.

\section{Submit your next manuscript to BioMed Central and take full advantage of:}

$\otimes$ Convenient online submission

$\otimes$ Thorough peer review

$\nabla$ No space constraints or color $₫$ gure charges

$\triangle$ Immediate publication on acceptance

$\triangle$ Inclusion in PubMed, CAS, Scopus and Google Scholar

$\otimes$ Research which is freely available for redistribution 